\title{
REVIEW
}

\section{Clinical review: Intrapericardial fibrinolysis in management of purulent pericarditis}

\author{
Pascal Augustin ${ }^{1 *}$, Mathieu Desmard', Pierre Mordant ${ }^{2}$, Sigismond Lasocki', Jean-Michel Maury², Nicholas Heming \\ and Philippe Montravers'
}

\begin{abstract}
Purulent pericarditis (PP) is a potentially life-threatening disease. Reported mortality rates are between 20 and $30 \%$. Constrictive pericarditis occurs over the course of PP in at least $3.5 \%$ of cases. The frequency of persistent PP (chronic or recurrent purulent pericardial effusion occurring despite drainage and adequate antibiotherapy) is unknown because this entity was not previously classified as a complication of PP. No consensus exists on the optimal management of PP. Nevertheless, the cornerstone of PP management is complete eradication of the focus of infection. In retrospective studies, compared to simple drainage, systematic pericardiectomy provided a prevention of constrictive pericarditis with better clinical outcome. Because of potential morbidity associated with pericardiectomy, intrapericardial fibrinolysis has been proposed as a less invasive method for prevention of persistent PP and constrictive pericarditis. Experimental data demonstrate that fibrin formation, which occurs during the first week of the disease, is an essential step in the evolution to constrictive pericarditis and persistent PP. We reviewed the literature using the MEDLINE database. We evaluated the clinical efficacy, outcome, and complications of pericardial fibrinolysis. Seventy-four cases of fibrinolysis in PP were analysed. Pericarditis of tuberculous origin were excluded. Among the 40 included cases, only two treated by late fibrinolysis encountered failure requiring pericardiectomy. No patient encountered clinical or echocardiographic features of constriction during follow-up. Only one serious complication was described. Despite the lack of definitive evidence, potential benefits of fibrinolysis as a less invasive alternative to surgery in the management of PP seem promising. Early consideration should be given to fibrinolysis in order to prevent both constrictive and persistent PP. Nevertheless, in case of failure of fibrinolysis, pericardiectomy remains the primary option for complete eradication of infection.
\end{abstract}

\section{Introduction}

Purulent pericarditis (PP) usually occurs in the compromised host [1]. Predisposing factors have changed over time. Pneumonia was the primary source of infection for the majority of patients $(72 \%)$ in the preantibiotic era, compared with only $22 \%$ of patients in the post-antibiotic era [2]. Nowadays, most cases of PP are healthcare associated. Bloodstream infections or underlying non-infectious conditions such as thoracic surgery, chronic kidney disease, immunosuppression, or malignancy (Table 1) are new predisposing factors.

Despite medical progress, PP is still associated with high mortality (20 to $30 \%$ ) attributed to both early and

\footnotetext{
*Correspondence: pascalaugustin@hotmail.com

'Département d'Anesthésie et Réanimation Chirurgicale, Hôpital Bichat Claude

Bernard, Assistance Publique - Hôpitaux de paris, Paris 7 University (Denis Diderot),

46 rue Henri-Huchard, 75877 Paris Cedex 18, France

Full list of author information is available at the end of the article
}

late complications, namely persistent $\mathrm{PP}$ and constrictive pericarditis $[1,2]$. These late complications may be prevented by early pericardiectomy, a surgical procedure known for its potential morbidity. Twenty years ago, intrapericardial fibrinolysis emerged as a promising alternative to surgery. Nevertheless, there is no consensus about its indication.

The history, pathophysiology, complications and surgical management of PP are described. In light of the physiological and histological data, we review the rationale of fibrinolysis in PP, the evidence for its efficacy, and all publications on indications, timing, results, and complications.

\section{Methods}

We searched for reported case series of PP managed with fibrinolysis. We reviewed the MEDLINE database since 1951. The following keywords were used: 'purulent pericarditis', 'infectious pericarditis,' 'constrictive pericarditis', 'fibrinolysis,' 'streptokinase' (SK), 'urokinase' (UK), 'tissue 
Table 1. Classification of purulent pericarditis according to source of infecting organism

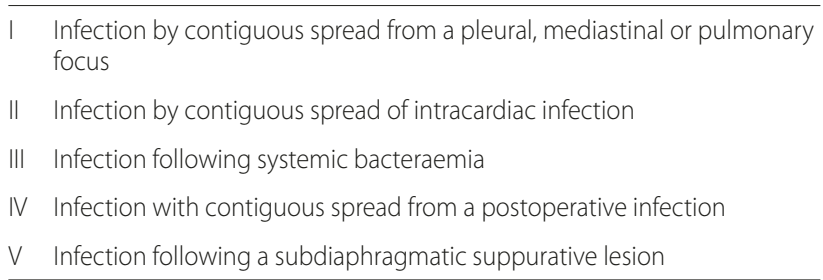

plasminogen activator' (tPA), and 'pericarditis'. We reviewed only English-language literature. We found 134 cases including 94 cases reported in one single study, providing pooled results of 60 tuberculous pericarditis patients and 34 PP patients. As patients with tuberculous pericarditis were excluded, only 74 cases were finally considered. As the specific outcome of the 34 PP cases was not available, our outcome analysis only focused on the 40 remaining cases [3].

Information related to modalities of administration, complications, and outcome of fibrinolysis was collected.

\section{Definitions and aetiologic classification}

$\mathrm{PP}$ is defined as a neutrophilic pericardial effusion infected by a bacterial, fungal, or parasitic agent. Tuberculous pericarditis is a lymphocytic effusion. Classification of PP comprises five aetiologic entities (Table 1) $[1,4]$. The advent of antibiotics has changed epidemiological and aetiopathogenic features. The median age of patients has increased from 21 to 49 years [2], whereas the overall frequency of PP has decreased. Before the antibiotic era, PP accounted for $40 \%$ of all cases of acute pericarditis and was related to the contiguous spread of lung infections in $72 \%$ of cases. Nowadays, pneumonia remains the primary source of infection in only $22 \%$ of cases while PP is mainly associated with healthcare and bloodstream infections $[1,2,5]$. For instance, oesophageal and cardiothoracic surgeries can be responsible for the direct inoculation of the pericardial space whereas immunosuppressive therapy, dialysis, and chemotherapy are relatively recent predisposing conditions $[2,4]$.

\section{Diagnosis}

The only way to diagnose PP is to obtain pericardial fluid for microbiological culture and direct microscopic examination. In a context of pneumonia, transthoracic echocardiography or computed tomography scan of the chest may disclose complications such as pleural empyema or pericardial effusion [6,7] (Figure 1). Interestingly, PP may have an insidious presentation without pericardial signs until occurrence of cardiac tamponade $[2,4,8,9]$ (Table 2). Indeed, in a postmortem series by Klacsmann and colleagues, among 55 cases of PP only 10 cases had been suspected and diagnosed ante mortem

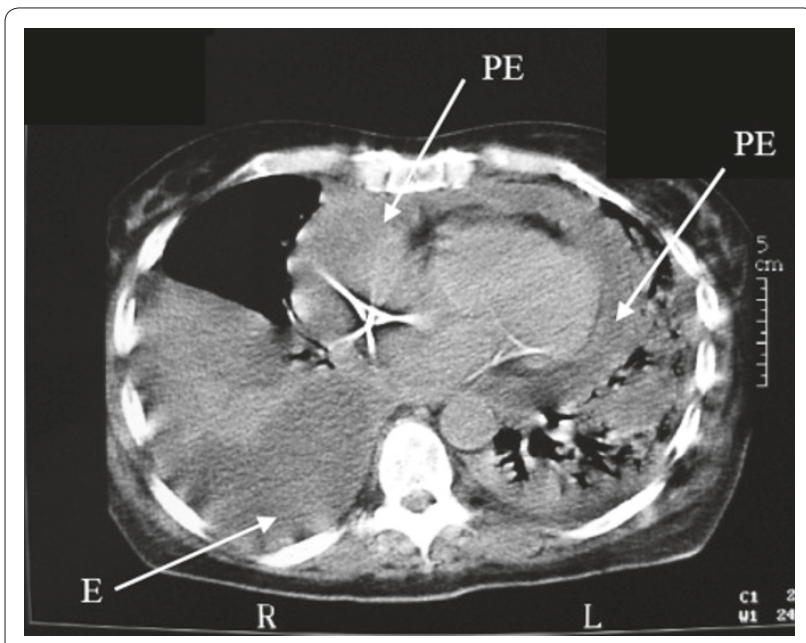

Figure 1. Computed tomography scan showing complications of pneumonia. Chest computed tomography scan of a patient with left alveolar pneumonia, complicated by empyema (E) and circumferential pericardial effusion (PE). $R$, right; $L$, left.

Table 2. Clinical features and complications of purulent pericarditis (from [2])

\begin{tabular}{lc}
\hline Clinical feature & \\
Duration of symptoms before presentation (days) & $7 \pm 3$ \\
Chest pain & 31 \\
Fever & 85 \\
Pericardial friction rub & 33 \\
Electrocardiographic abnormalities & 45 \\
Complication & \\
Death & 29 \\
Cardiac tamponade & 15
\end{tabular}

Data presented as mean \pm standard deviation or percentage.

[1]. Poor diagnostic performance of the condition results in late diagnosis, at an advanced stage, after onset of pericardial adhesions [10].

\section{Complications}

PP may lead to cardiac tamponade and septic shock. The treatment of these conditions has no specificity. On the contrary, constrictive pericarditis and persistent PP two late-stage complications - imply specific considerations and management $[1,4]$.

Constrictive pericarditis is defined by the thickening and fusion of the pericardium causing low pericardial compliance and right heart failure. Haemodynamic compromise and low cardiac output may ensue because of adiastoly or impaired cardiac filling. Pericardial fibrosis is caused by chronic/subacute inflammation inducing fibroblast proliferation and collagen deposition. Two large reviews found the same frequency of $3.5 \%$ for 
constrictive pericarditis during the course of PP [2,11]. In one smaller study with long-term follow-up, however, constrictive pericarditis occurred in $57 \%$ of cases, with few cases occurring during the first year.

We propose an original definition for persistent PP. This entity is defined by a chronic or recurrent purulent pericardial effusion occurring despite drainage and adequate antibiotherapy. This feature is well described in case reports. Persistence of PP is associated with occurrence of pericardial adhesions and loculation of pericardial effusion due to the presence of thick fibrin clots preventing complete evacuation of pus through pericardial drains or pericardiostomy [12-17]. Purulent discharge persists during several weeks and may lead to death due to septic shock or tamponade. At the stage of persistent PP, pericardiectomy is challenging and associated with high morbidity because of pericardial adherences and areas of fusion. Moreover, patients present with impaired general status [12-17]. Interestingly, this entity has not been previously defined or classified as a late complication of PP, resulting in a lack of epidemiological data. Finally, because of chronic inflammation, persistent PP may promote constrictive pericarditis. Nevertheless, these two entities have distinct clinical and pathophysiological features.

\section{Pathophysiology of purulent pericarditis and of its complications}

PP shares pathophysiological similarities with empyema. In the case of empyema, the contiguous spread of pneumonia causes pleural mesothelial barrier dysfunction leading to exudative pleural effusion [18]. The second step is bacterial invasion, which attracts leucocytes. Activated leucocytes promote coagulation, resulting in fibrin formation [19]. Fibrin deposits are responsible for pleural adhesion, thickening, and loculation of effusion, therefore preventing easy drainage and antibiotic diffusion. When the process is prolonged, inflammation leads to fibrosis due to collagen secretion.

Experimental models argue for a similar pathophysiological process in PP, leading from pericardial inflammation to pericardial adhesion and fibrosis $[20,21]$. These studies indicate that pericardial loculation and intrapericardial fibrosis may occur respectively 1 week and 2 weeks after onset of the disease [20,21].

Furthermore, these studies show that fibrin formation is the cornerstone in the pathogenesis of both persistent PP and constrictive pericarditis. Fibrin may thus be a target in the management of PP.

\section{General management, surgery and fibrinolysis General medico-surgical management}

Management of PP requires a combined surgical and medical approach with complete drainage of the effusion

\section{Table 3. Different surgical modalities for pericardial} effusion evacuation

\begin{tabular}{ll}
\hline I & Subxiphoid percutaneous catheter \\
II & Subxiphoid tube drain \\
III & Subxiphoid tube or percutaneous catheter and fibrinolysis \\
IV & Pericardial window and pleural drain \\
V & Partial pericardiectomy with pericardial tube \\
VI & Anterior interphrenic pericardiectomy \\
VII & Total pericardiectomy \\
\hline
\end{tabular}

Adapted from [25].

and complementary antibiotherapy. Antibiotic regimen is initially empirical and should target Staphylococcus aureus. Anaerobes and Gram-negative bacteria should be targeted in case of a digestive origin [22,23]. In recently hospitalised patients, methicillin-resistant Staphylococcus should be considered [23]. Considering the lack of guidelines on the duration of antibiotherapy in PP and by analogy with empyema, a treatment of at least 3 weeks seems reasonable [24]. Moreover, antibiotherapy should be maintained until removal of the focus of infection, and until improvement of clinical and biological signs.

\section{Surgery}

Until 1941 the mortality of PP was estimated to be 100\% in untreated cases. Pericardiostomy decreased mortality to about $50 \%$, and to $30 \%$ when associated with antibiotics [17]. Eradication of infected pericardial fluid is the cornerstone of PP therapy, although the way to obtain eradication remains controversial (Table 3) [25]. Guidelines from the European Society of Cardiology make the following statement: 'Frequent irrigation of the pericardial cavity with UK or SK, using large catheters, may liquefy the purulent exudate, but open surgical drainage through subxiphoid pericardiotomy is preferable' [26]. Because of loculations and adhesions, simple evacuation by surgical or percutaneous drainage may not prevent constrictive pericarditis or persistent PP [25,27-29]. To avoid these complications, invasive surgical treatment has been advocated. In a retrospective series, partial pericardial resection or total pericardiectomy seem to be associated with a better outcome than simple pericardial drainage $[4,10,25,27,29]$ (Table 4). Taken together these studies suggest a curative role of pericardiectomy by achieving complete eradication of the infection and a role in preventing persistent $\mathrm{PP}$ and constrictive pericarditis.

Despite these convincing data, physicians are reluctant to perform preventive surgery associated with potential serious complications. Nevertheless, this procedure could be easier early in the disease, before apparition of adhesions. Furthermore, operative mortality is related to the preoperative disability of patients $[30,31]$ and haemodynamic compromise is rarely observed at an early stage. 
Table 4. Outcome according to management with primary pericardiectomy or pericardiocentesis

\begin{tabular}{lcc}
\hline & \multicolumn{2}{c}{ Mortality } \\
\cline { 2 - 3 } Reference & Pericardiectomy & Pericardiocentesis \\
\hline$[4]^{\mathrm{a}}$ & - & $5 / 11(45)$ \\
{$[27]^{\mathrm{b}}$} & $0 / 4(0)$ & - \\
{$[29]^{\mathrm{c}}$} & $8 / 50(16)$ & $20 / 31(65)$ \\
{$[25]^{\mathrm{d}}$} & $1 / 13(8)$ & - \\
{$[10]^{\mathrm{e}}$} & $0 / 1(0)$ & $3 / 14(21)$ \\
\hline
\end{tabular}

Data presented as $n$ (\%). apericardiocentesis: rescue pericardiectomy in four

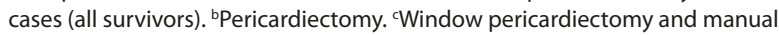

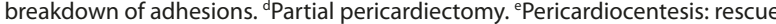
pericardiectomy in six cases (five survivors).

Some authors therefore advocate a systematic early preventive pericardiectomy [32].

\section{Fibrinolysis}

Intrapericardial fibrinolysis, a less invasive procedure, has been proposed as an alternative to surgery for PP management. The objective of fibrinolysis is to target fibrin formation, to optimise evacuation of a thick fluid, and therefore to prevent both persistent PP and constrictive pericarditis.

\section{Rationale of intrapericardial fibrinolysis}

Fibrinolysis in PP follows the same rationale as that in empyema. In the latter, surgery also has better results than simple drainage. Many authors have attempted to demonstrate the efficacy of intrapleural fibrinolysis compared with simple drainage for prevention of persistent empyema requiring surgical debridement. Efficacy of fibrinolysis was demonstrated in a randomised controlled trial (RCT) and a meta-analysis [33,34]. In a double-blind RCT including 44 patients, Diacon and colleagues found a better clinical outcome and fewer referrals to surgery in the SK group [33]. Unexpectedly, the largest RCT testing the efficacy of SK in empyema did not find any significant difference between both groups [35]. The group of 208 patients assigned to SK treatment had the same rate of referrals to surgery as the group of 222 patients who received normal saline. The population of this study was heterogeneous and the timing of fibrinolysis was late, however, suggesting that fibrinolysis may still be useful in subgroups of younger patients treated earlier.

\section{Evidence of pericardial fibrinolysis efficacy}

Given the similarities between empyema and PP, fibrinolysis has been considered in PP. The first cases of successful management of PP with fibrinolysis were reported in 1951 [12,14]. These patients had chronic PP persisting and relapsing despite pericardiostomy and antibiotics. Fibrinolysis was successfully administered at a late stage as a rescue treatment, allowing complete evacuation of purulent material. Forgotten for 30 years, the treatment was rediscovered in 1984 by Bennett [13]. Efficacy of fibrinolysis was also demonstrated in an experimental model of acute pericarditis in dogs [21]. Fibrinolysis or normal saline was applied through a pericardial drain daily from the third through sixth day after instillation of the irritant mixture. Clinical and histological patterns of constrictive pericarditis were evaluated over a 60-day period. All 11 animals assigned to the normal saline group developed pericardial thickening and adhesions. Among these, nine animals demonstrated clinical features of constrictive pericarditis. One-half of the 10 animals in the UK group did not demonstrate any sign of constriction or any histological changes of the pericardium.

Clinical data on fibrinolysis in PP exist. All cases of fibrinolysis in PP available in the English-language literature are summarised in Table 5. There is great heterogeneity in the different protocols used. Among 40 analysable cases, we found two cases of failure requiring pericardiectomy with a favourable outcome. Out of two described deaths, only one was due to PP. No sign of clinical constriction at hospital discharge was observed for the 35 remaining patients (data not provided for three patients). During follow-up, no constriction was found in patients for whom data were available (20 patients on clinical examination and 12 patients on transthoracic echocardiography).

One RCT with long-term follow-up (mean $57 \pm 29$ months) assessed the efficacy of fibrinolysis in PP [3]. Unfortunately, the study population included both tuberculous pericarditis $(n=60)$ and PP $(n=34)$. Compared with tuberculous pericarditis, PP was 10 times $(P<0.0001)$ more likely to be associated with constrictive pericarditis on transthoracic echocardiography. Fibrinolysis lowered pericardial thickening, and decreased the rate of constrictive pericarditis by $38.3 \%$ (hazard ratio $=0.185$, $P<0.0001)$. The length of evolution of the disease before treatment was also predictive of constrictive pericarditis. Interestingly, the rate of constrictive pericarditis was much higher than in previous reports $(3.5 \%$ vs. $57 \%$ in placebo group), but follow-up was much longer. Constriction occurred with a mean delay of 11 months. We cannot draw any definitive conclusion from this study since no subgroup analysis was performed in the PP population.

\section{Timing of fibrinolysis in PP}

There is no consensus on the appropriate timing of fibrinolysis (Table 5). Two main options can be distinguished: primary fibrinolysis performed immediately after drain insertion, and rescue fibrinolysis applied in cases of recurrence or incomplete evacuation of pus. Among published articles, we only found cases of failure when fibrinolysis had been applied late. At this stage, 


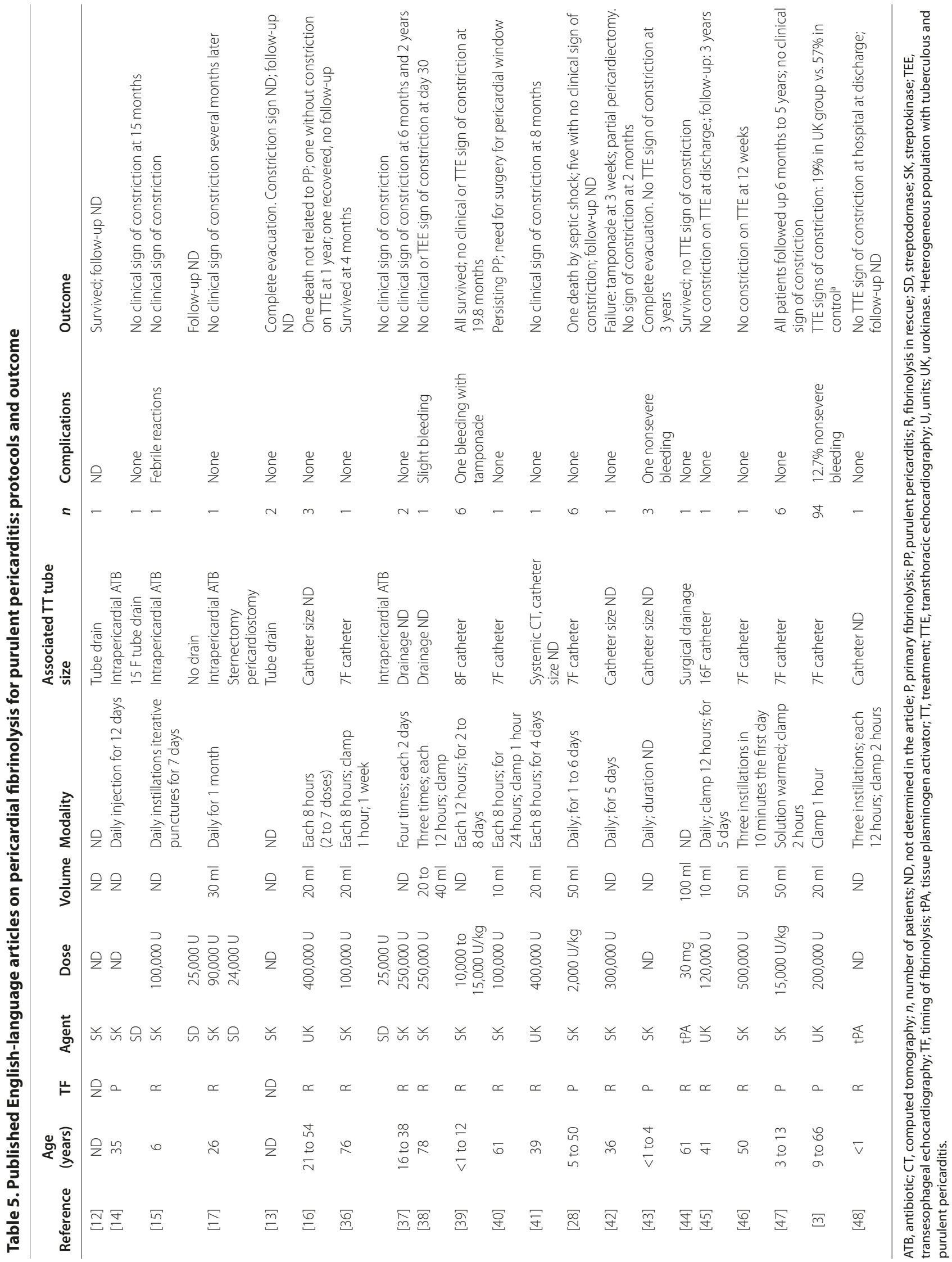




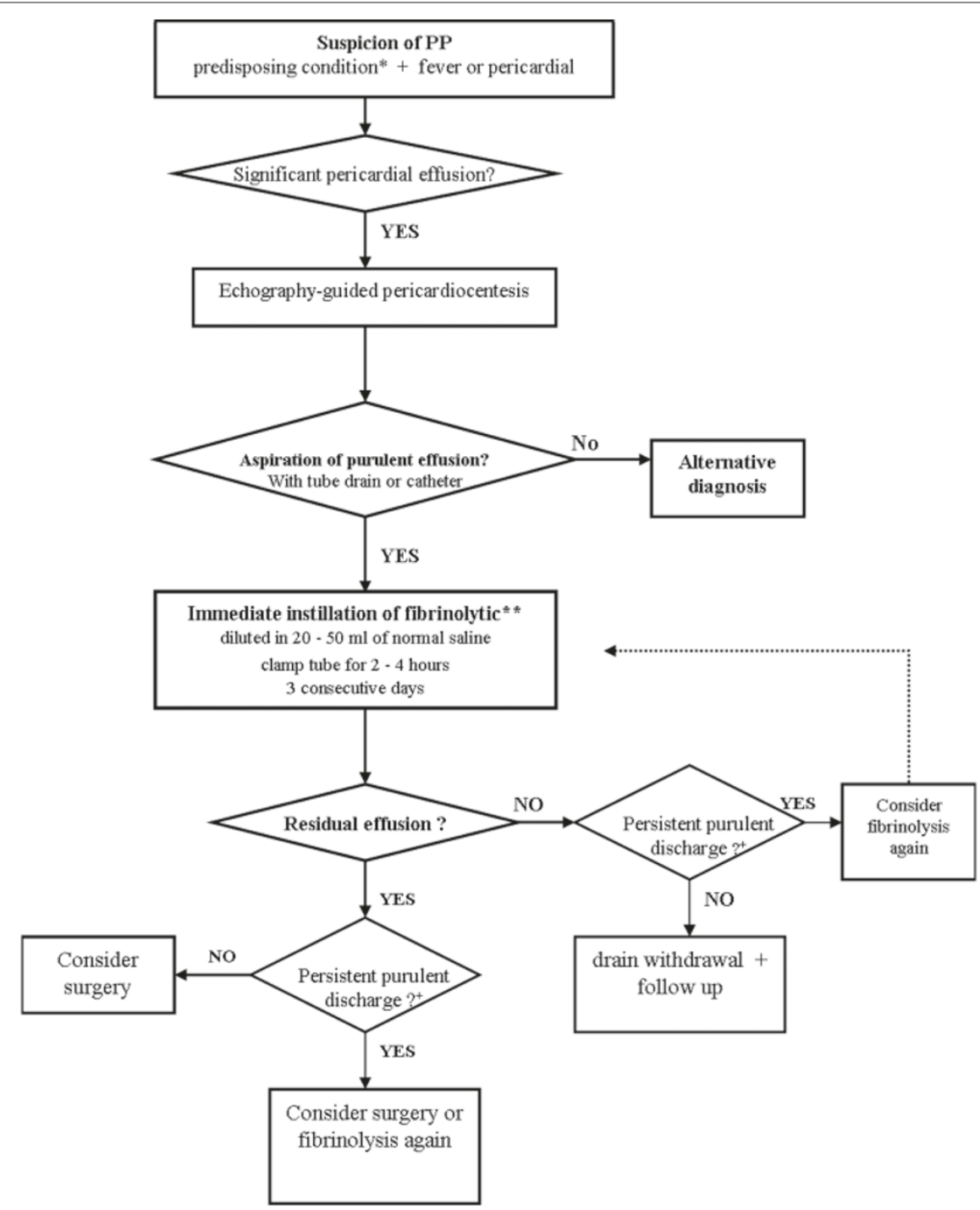

Figure 2. Flow diagram describing the proposed algorithm for diagnosis and management of purulent pericarditis. ${ }^{*}$ In relation to aetiologic classification (Table 1). ${ }^{*}$ |f no haemorrhagic complication of pericardial drainage. ${ }^{+}$If catheter/drain is permeable. PP, purulent pericarditis.

thick loculations cannot be liquefied by fibrinolytic agent $[40,42]$ (Table 5). Furthermore, fibrinolytic agents can only dissolve fibrin, but have no effect on fibrosis. Two experimental studies indicate that fibrin influx increases during the first week of the disease and that fibrosis may appear after 2 weeks [20,21]. These studies suggest that earlier administration may lead to optimal outcomes. Nevertheless, data regarding optimal timing are solely based on animal models and on a few case reports, limiting the ability to make a definitive statement.

\section{Optimal fibrinolytic dose and volume}

SK, UK and tPA have all been used in pericardial fibrinolysis. Dose comparison between tPA and UK found an equivalence of 36,000 units UK for $1 \mathrm{mg}$ tPA [49]. Most studies of fibrinolysis in PP used SK. Because of the risk of allergy, however, using UK or tPA has been suggested [50]. Owing to the lack of guidelines, there is large variability in fibrinolytic dosing in the reported cases. UK was used at a dose of 400,000 units in four cases and 200,000 units in another study, diluted in $20 \mathrm{ml}$ normal saline. The British Thoracic Society guidelines for the management of pleural infection propose instillation of 250,000 UI SK daily or twice daily or of 100,000 UI UK daily [24]. A dose of $10 \mathrm{mg}$ tPA has been proposed in empyema [51]. There are no definitive data on the appropriate dose of these three fibrinolytic agents. Given the different regimens previously used in PP (Table 5) and the doses proposed by the British Thoracic Society and the American Thoracic Society for treating empyema, 
reasonable options may be daily instillations of 250,000 UI SK, 200,000 UI UK or $10 \mathrm{mg}$ tPA. Each instillation should be diluted in a volume of at least $20 \mathrm{ml}$ normal saline to ensure adequate diffusion into the pericardial space. Fibrinolytic agents must be retained in the pericardial space by clamping the drain for 2 to 4 hours. Treatment may be repeated for three consecutive days to achieve complete pericardial drainage, assessed by echocardiography (Figure 2).

\section{Failure and complications of fibrinolysis}

In case of fibrinolysis failure, resulting in incomplete drainage despite three consecutive instillations of fibrinolytic agent associated with adequate antibiotherapy, a surgical approach should be considered. Given the prognosis and the general status of the patient, radical pericardiectomy should only be performed if its benefits are believed to outweigh the potential drawbacks.

Three complications of fibrinolysis can theoretically occur. Even if allergy is a well-known side effect of fibrinolysis after repeated instillation of SK, treatment with UK or tPA greatly reduces this risk [50]. The second risk is major haemorrhage. Only one case of haemorrhagic tamponade after fibrinolysis has been described [39]. This could be a consequence of PP and not directly related to fibrinolysis. Fibrinolysis for empyema is not associated with bleeding events $[33,35]$. Indeed, fibrinolysis in PP has no systemic effect detected on coagulation laboratory tests [28]. The third risk is cardiac tamponade, which could occur if the instilled volume is not evacuated by the pericardial drain. The pressure-volume curve (Figure 3) described in the experimental study published by Refsum and colleagues illustrates that the addition of a small volume of liquid may provoke cardiac compression [52]. This risk could be increased in the later stage of the disease, characterised by low pericardial compliance secondary to fibrosis. In fact, no tamponade due to intrapericardial administration of fibrinolysis has been described. The risk of tamponade could be lowered if the volume of fibrinolytic agent instilled is inferior to the amount of fluid drained immediately beforehand.

Definitive conclusions on the risks and complications of intrapericardial fibrinolysis cannot be made with the evaluation of 74 case reports. Potential benefits of fibrinolysis seem to outweigh its apparent low morbidity.

\section{Conclusion}

PP managed with simple pericardial drainage may evolve to constrictive and persistent PP. Despite the lack of definitive evidence, intrapericardial fibrinolysis may be an alternative to pericardiectomy as a treatment for PP and for prevention of persistent PP and constrictive pericarditis. Clinical and experimental data demonstrate that features of irreversible fibrosis may appear after

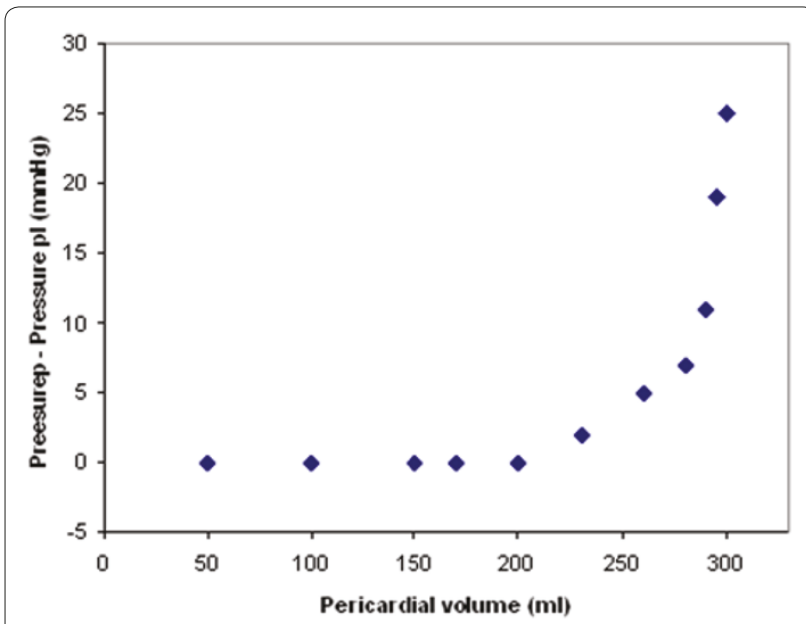

Figure 3. Pericardial pressure-volume curve. Adapted with permission from [52].

2 weeks. Considering that diagnosis of PP is often delayed, early consideration should therefore be given to fibrinolysis to ensure optimal efficacy. Complications of intrapericardial fibrinolysis have only exceptionally been reported. Physicians should thus not be reluctant to apply this promising technique. Nevertheless, in cases of failure of fibrinolysis, pericardiectomy remains the primary option to consider for complete eradication of infection and prevention of persistent PP and constrictive pericarditis.

\section{Abbreviations}

$\mathrm{PP}$, purulent pericarditis; $\mathrm{RCT}$, randomised controlled trial; SK, streptokinase; tPA, tissue plasminogen activator; UK, urokinase.

\section{Competing interests}

The authors declare that they have no competing interests.

\section{Author details}

'Département d'Anesthésie et Réanimation Chirurgicale, Hôpital Bichat Claude Bernard, Assistance Publique - Hôpitaux de paris, Paris 7 University (Denis Diderot), 46 rue Henri-Huchard, 75877 Paris Cedex 18, France. ${ }^{2}$ Department of Thoracic Surgery, Hôpital Bichat-Claude Bernard, Assistance Publique Hôpitaux de paris, Paris 7 University (Denis Diderot), 46 rue Henri-Huchard, 75877 Paris Cedex 18, France.

Published: 20 April 2011

\section{References}

1. Klacsmann PG, Bulkley BH, Hutchins GM: The changed spectrum of purulent pericarditis: an 86 year autopsy experience in 200 patients. Am J Med 1977, 63:666-673.

2. Parikh SV, Memon N, Echols M, Shah J, McGuire DK, Keeley EC: Purulent pericarditis, report of 2 cases and review of the literature. Medicine 2009, 88:52-65.

3. Cui HB, Chen XY, Cui CC, Shou XL, Liu XH, Yao XW, Wang JK, Guan GC: Prevention of pericardial constriction by transcatheter intrapericardial fibrinolysis with urokinase. Chin Med Sci J 2005, 20:5-10.

4. Rubin RH, Moellering RC, Jr: Clinical, microbiologic and therapeutic aspects of purulent pericarditis. Am J Med 1975, 59:68-78

5. Branch CF: Pathology of pericarditis. N Engl J Med 1933, 208:771-788.

6. Donnelly LF, Klosterman LA: The yield of CT of children who have complicated pneumonia and non-contributory chest radiography. Am J 
Roentgenol 1998, 170:1627-1631.

7. Tan Kendrick AP, Ling H, Subramaniam R, Joseph VT: The value of early CT in complicated childhood pneumonia. Pediatr Radiol 2002, 32:16-21.

8. Kauffman CA, Watanakunakorn C, Phair JP: Purulent pneumococcal pericarditis. A continuing problem in the antibiotic era. Am J Med 1973, 54:743-750.

9. Arsura EL, Kilgore WB, Strategos E: Purulent pericarditis misdiagnosed as septic shock. South Med J 1999, 92:285-288.

10. Sagrista-Sauleda J, Barrabes JA, Permanyer-Miralda G, Soler-Soler J: Purulent pericarditis: review of a 20-year experience in a general hospital. $J$ Am Coll Cardiol 1993, 22:1661-1665

11. Gaudelus J, Leraillez J, Dandine M, Nathanson M, Perelman R: Péricardite purulente d'évolution constrictive subaiguë. A propos d'un cas. Revue de la littérature. Sem Hop 1983, 59:1527-1532.

12. Wright LT: Use of streptokinase-dornase in certain surgical conditions. J Int Coll Surg 1951, 15:286-298.

13. Bennett EV, Jr: Purulent pericarditis. J Thorac Cardiovasc Surg 1984 87:641-642

14. Adie GC, Childress WG: Experiences with streptokinase and streptodornase. Ann Surg 1951, 134:659-671.

15. Lundstrom R: Purulent pericarditis and empyema caused by Hemophilus influenzae, type B. Am Heart J 1955, 49:108-115.

16. Winkler WB, Karnik R, Slany J: Treatment of exudative fibrinous pericarditis with intrapericardial urokinase. Lancet 1994, 344:1541-1542.

17. Schweitzer RJ: Purulent pericarditis; management with surgical drainage and enzymatic debridement. Am J Surg 1956, 91:906-910.

18. Mohammed KA, Nasreen N, Hardwick J, Logie CS, Patterson CE, Antony VB: Bacterial induction of pleural mesothelial monolayer barrier dysfunction Am J Physiol Lung Cell Mol Physiol 2001, 281:119-125.

19. Rahman NM, Gleeson FV: New directions in the treatment of infected pleural effusions. Clin Radio/ 2006, 61:719-722.

20. Leak LV, Ferrans VJ, Cohen SR, Eidbo EE, Jones M: Animal model of acute pericarditis and its progression to pericardial fibrosis and adhesions: ultrastructural studies. Am J Anat 1987, 180:373-390

21. Pan HL, Liu J, Zhang YD: Effect of intrapericardial administration of urokinase on experimental constrictive pericarditis [abstract]. J Am Coll Cardiol 1994, 23(Suppl 1):46A.

22. Brook I, Frazier EH: Microbiology of acute purulent pericarditis. A 12-year experience in a military hospital. Arch Intern Med 1996, 156:1857-1860

23. Brook I: Pericarditis due to anaerobic bacteria. Cardiology 2002, 97:55-58.

24. Davies CWH, Gleeson FV, Davies RJO; on behalf of BTS Pleural Disease Group subgroup of the BTS Standards of Care Committee: BTS guidelines for the management of pleural infection. Thorax 2003, 58(Suppl 2):18-28.

25. Majid AA, Omar A: Diagnosis and management of purulent pericarditis. Experience with pericardiectomy. J Thorac Cardiovasc Surg 1991 102:413-417.

26. Maisch B: Guidelines on the diagnosis and management of pericardial diseases - executive summary. Eur Heart J 2004, 25:587-610.

27. Sethi GK, Nelson RM, Jenson CB: Surgical management of acute septic pericarditis. Chest 1973, 63:732-735

28. Ustunsoy H, Celkan MA, Sivrikoz MC, Kazaz H, Kilinc M: Intrapericardial fibrinolytic therapy in purulent pericarditis. Eur J Cardiothorac Surg 2002, 22:373-376.

29. Corachan M, Poore P, Hadley GP, Tanner A: Purulent pericarditis in Papua New Guinea: report of 12 cases and review of the literature in a tropical environment. Trans R Soc Trop Med Hyg 1983, 77:341-343.

30. McCaughan BC, Schaff HV, Piehler JM, Danielson GK, Orszulak TA, Puga FJ, Pluth JR, Connolly DC, MCGoon DC: Early and late results of pericardiectomy for constrictive pericarditis. J Thorac Cardiovasc Surg 1985, 89:340-350

31. Bertog SC, Thambidorai SK, Parakh K, Schoenhagen P, Ozduran V, Houghtaling PL, Blackstone EH, Lauer MS, Klein AL: Constrictive pericarditis: etiology and cause specific survival after pericardiectomy. J Am Coll Cardiol 2004, 43:1445-1452.

32. DeValeria PA, Baumgartner WA, Casale AS, Greene PS, Cameron DE, Gott VL,
Watkins L, Jr, Reitz BA: Current indications, risks, and outcome after pericardiectomy. Ann Thorac Surg 1991, 52:219-224.

33. Diacon AH, Theron J, Schuurmans MM, Van de Wall BW, Bolliger CT: Intrapleural streptokinase for empyema and complicated parapneumonic effusions. Am J Respir Crit Care Med 2004, 170:49-53.

34. Cameron R, Davies HR: Intra-pleural fibrinolytic therapy versus conservative management in the treatment of parapneumonic effusions and empyema. Cochrane Database Syst Rev 2008, 16:CD002312.

35. Maskell NA, Davies CW, Nunn AJ, Hedley EL, Gleeson FV, Miller R, Gabe R, Rees GL, Peto TE, Woodhead MA, Lane DJ, Darbyshire JH, Davies RJ; First Multicenter Intrapleural Sepsis Trial (MIST1) Group: U.K. controlled trial of intrapleural streptokinase for pleural infection. N Engl J Med 2005, 352:865-874.

36. Mann-Segal DD, Shanahan EA, Jones B, Ramasamy D: Purulent pericarditis: rediscovery of an old remedy. J Thorac Cardiovasc Surg 1996, 111:487-488

37. Defouilloy C, Meyer G, Slama M, Galy C, Verhaeghe P, Touati G, Ossart M: Intrapericardial fibrinolysis: a useful treatment in the management of purulent pericarditis. Intensive Care Med 1997, 23:117-118.

38. Maynar J, Corral E, Manzano A, Fonseca F, Ulibarrena MA, Cantabrana S, Labayen F: Intrapericardial streptokinase fibrinolysis in the management of purulent pneumococcal pericarditis. Intensive Care Med 1997, 23:925-926.

39. Juneja R, Kothari SS, Saxena A, Sharma R, Johi A: Intrapericardial streptokinase in purulent pericarditis. Arch Dis Child 1999, 80:275-277.

40. Bridgman PG: Failure of intrapericardial streptokinase in purulent pericarditis [letter]. Intensive Care Med 2001, 27:942.

41. Schafer M, Lepori M, Delabays A, Ruchat P, Schaller MD, Broccard AF: Intrapericardial urokinase irrigation and systemic corticosteroids: an alternative to pericardectomy for persistent fibrino-purulent pericarditis. Cardiovasc Surg 2002, 10:508-511.

42. Keersmaekers T, Elshot SR, Sergeant PT: Primary bacterial pericarditis. Acta Cardio/ 2002, 57:387-389.

43. Cakir O, Gurkan F, Balci AE, Eren M, Dikici B: Purulent pericarditis in childhood: ten years of experience. J Pediatr Surg 2002, 37:1404-1408.

44. Reznikoff CP, Fish JT, Coursin DB: Pericardial infusion of tissue plasminogen activator in fibropurulent pericarditis. J Intensive Care Med 2003, 181:47-51.

45. Kamimura M, Suzuki T, Kudo K: Intrapericardial infusion of urokinase for the treatment of purulent pericarditis. Intern Med 2002, 41:412-413.

46. Tomkowski WZ, Gralec R, Kuca P, Burakowski J, Caban P, Orlowski T, Kurzyna $M$ : Effectiveness of intrapericardial administration of streptokinase in purulent pericarditis. Herz 2004, 29:802-805.

47. Ekim H, Demirbağ R: Intrapericardial streptokinase for purulent pericarditis. Surg Today 2004, 34:569-572

48. Bigham MT, Brady PW, Manning PB, Jacobs BR, Kimball TR, Wong HR: Therapeutic application of intrapericardial tissue plasminogen activator in a 4-month-old child with complex fibropurulent pericarditis. Pediatr Crit Care Med 2008, 9:e1-e4

49. Clase CM, Crowther MA, Ingram AJ, Cinà CS: Thrombolysis for restoration of patency to haemodialysis central venous catheters: a systematic review. J Thromb Thrombolysis 2001, 11:127-136.

50. Tsang TS, Califf RM, Stebbins AL, Lee KL, Cho S, Ross AM, Armstrong PW: Incidence and impact on outcome of streptokinase allergy in the GUSTO-I trial. Am J Cardiol 1997, 79:1232-1235.

51. Light RW: Parapneumonic effusions and empyema. Proc Am Thorac Soc 2006, 3:75-80.

52. Refsum H, Jonemann M, Lipton MJ, Skiolbebrand C, Carlsson E, Tyberg JV: Ventricular diastolic pressure-volume relations and the pericardium. Effects of changes in blood volume and pericardial effusion in dogs. Circulation 1981, 64:997-1004.

\section{doi:10.1186/cc10022}

Cite this article as: Augustin P, et al.: Clinical review: Intrapericardial fibrinolysis in management of purulent pericarditis. Critical Care 2011 $15: 220$ 